\title{
An Overview of Different Reconstruction Options after Resection of Distal Radius Neoplasms
}

\author{
Zeeshan Khan ${ }^{1}$, Ashish Gulia ${ }^{2}$ and Israr Ahmad ${ }^{3 *}$ \\ ${ }^{1}$ Assistant Professor \& Consultant Orthopaedic and Sarcoma surgeon, Pakistan \\ ${ }^{2}$ Associate Professor \& Consultant Orthopaedic Oncologist, India \\ ${ }^{3}$ Associate Professor of Orthopaedics, Pakistan \\ *Corresponding author: Israr Ahmad, Associate Professor of Orthopaedics, Hayatabad Medical Complex Peshawar, Pakistan
}

Submission: 眥 February 02, 2018; Published: 眥June 25, 2018

\begin{abstract}
Distal radius is a common site for giant cell tumours, with high grade lesions having a higher recurrence rate and hence requires resection with clear margins and reconstruction. This site because of its unique anatomical features offers a challenge to the surgeons when reconstructing the defect left after resection of tumors. Various techniques including autografts, allografts and endoprosthetic reconstruction have been described in literature with their benefits and disadvantages. It is suggested that one is aware of all these options but best to use a technique depending on the experience of the surgeon and availability of graft or prosthesis.
\end{abstract}

Keywords: Distal radius; Tumours; Sarcoma; Reconstruction

\section{Introduction}

I The distal radius is a common site for giant cell tumours (GCT) but not so common for primary malignancies. It is accounted for as the 3rd commonest site for GCT. These tumours commonly present with pain, lump and stiffness and sometimes as a pathological fracture

The unique anatomy of the distal end of the radius due to the presence of various anatomical structures including numerous tendons, nerves and blood vessels and at the same time the lack of soft tissue cover makes any resection and reconstruction around this area challenging. Various techniques have been described in the literature for reconstruction of the residual defect after resection of distal radius tumours. As patient survivorship has improved particularly with malignant cases, the expectations have increased as well and patients demand a stable and functional construct after surgery. The variety of reconstruction techniques explains the relative success with each and points to a lack of a standard regime. The aim of any surgery is complete removal of the tumour and to maintain as much function as possible. This article will review all these techniques described in the current literature along with its pros and cons. Due to the varied nature of pathologies and presentation, it is impossible to draw an algorithm for treatment.

\section{Reconstruction Challenges}

There are various reasons why reconstruction in the distal end of radius is demanding. Some of these include the unique anatomy, mode of presentation and the availability of allografts and prosthesis, if they are being used.

\section{Reconstruction Options}

In order to reconstruct the defect after resection of tumour, the options can broadly be classified into biological and non-biological types. The type of reconstruction method depends on the extent of defect, nature of pathology and also surgeon familiarity and experience with these methods.

\section{Biological reconstruction}

This involves reconstruction of the defect with either autograft, allograft, ulna centralisation or ulna translocation. Perhaps the most commonly described reconstruction technique in the literature is the use of the fibula as autograft which can either be vascular or avascular.

These biological reconstructions techniques can be further divided into autografts and allografts.
A. Autografts
1. Non vascularised fibula
2. Vascularised fibula
3. Ulna translocation
4. Tibia cortical strut 
5. Iliac crest autograft.

B. Allografts

1. Osteoarticular allograft.

Autografts: Fibula can be used to reconstruct the residual defect either from the diaphyseal section if arthrodesis is planned or the proximal fibula with the head if an arthroplasty is planned. The fibula head resembles the distal end of the radius and can form a nice articulating surface with the proximal carpal row [14]. This is due to the plastic deforming quality of the fibula head where some remoulding occurs. This in turn can either be vascular or avascular. The choice depends on the expertise and availability of microvascular reconstruction surgeon for vascularised fibula and to some extent by the size of the defect. Larger defects are thought to be best reconstructed with a vascularised graft. The vascularised fibula autograft was described first in the literature by Taylor and McKee et al [5-6]. The potential advantages of a vascularized graft as shown by some are quicker union, reduction in non-union incidence, reduced incidence of fractures due to its mechanical strength and low rates of infection [7-8]. Non-vascularised bone grafts potentially lack these advantages but have still shown good results [9] (Figure 1). The potential complications associated with fibula autograft include delayed union, nonunion, stress fractures, bone resorption, deformities, ulnar impingement, carpal degenerative changes and donor site morbidity [10].
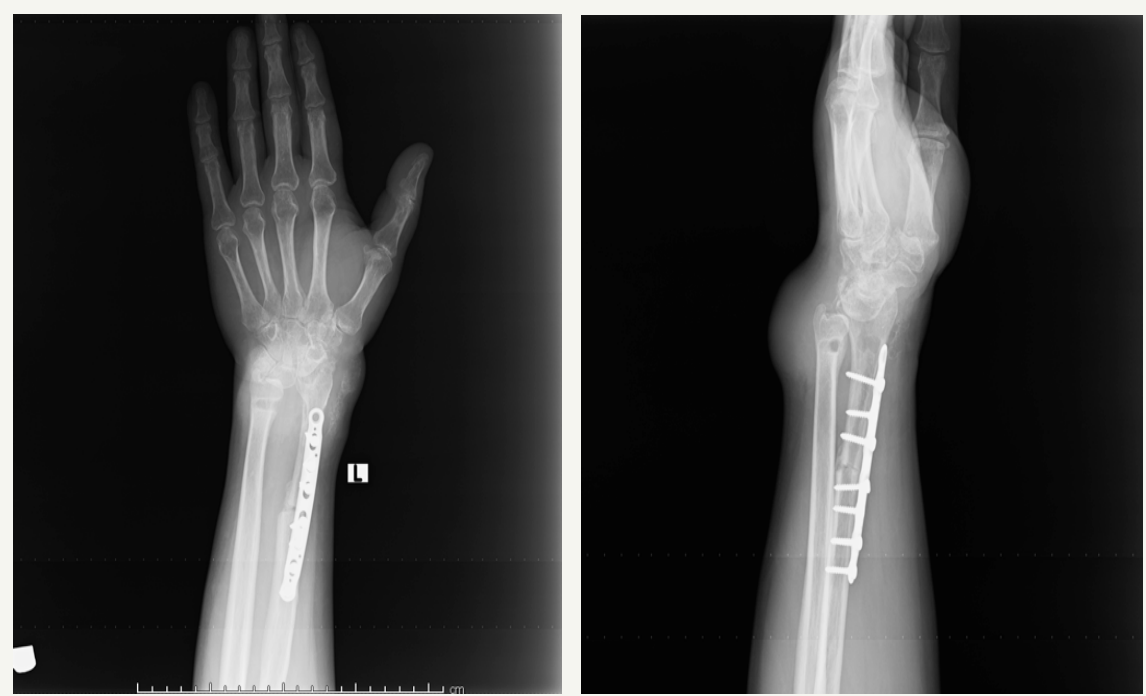

Figure 1: AP and lateral radiograph of a distal radius giant cell tumour resected and reconstructed with non-vascularised fibula autograft with wrist arthroplasty. Soft tissue lump on the dorsum depicts recurrence of disease.
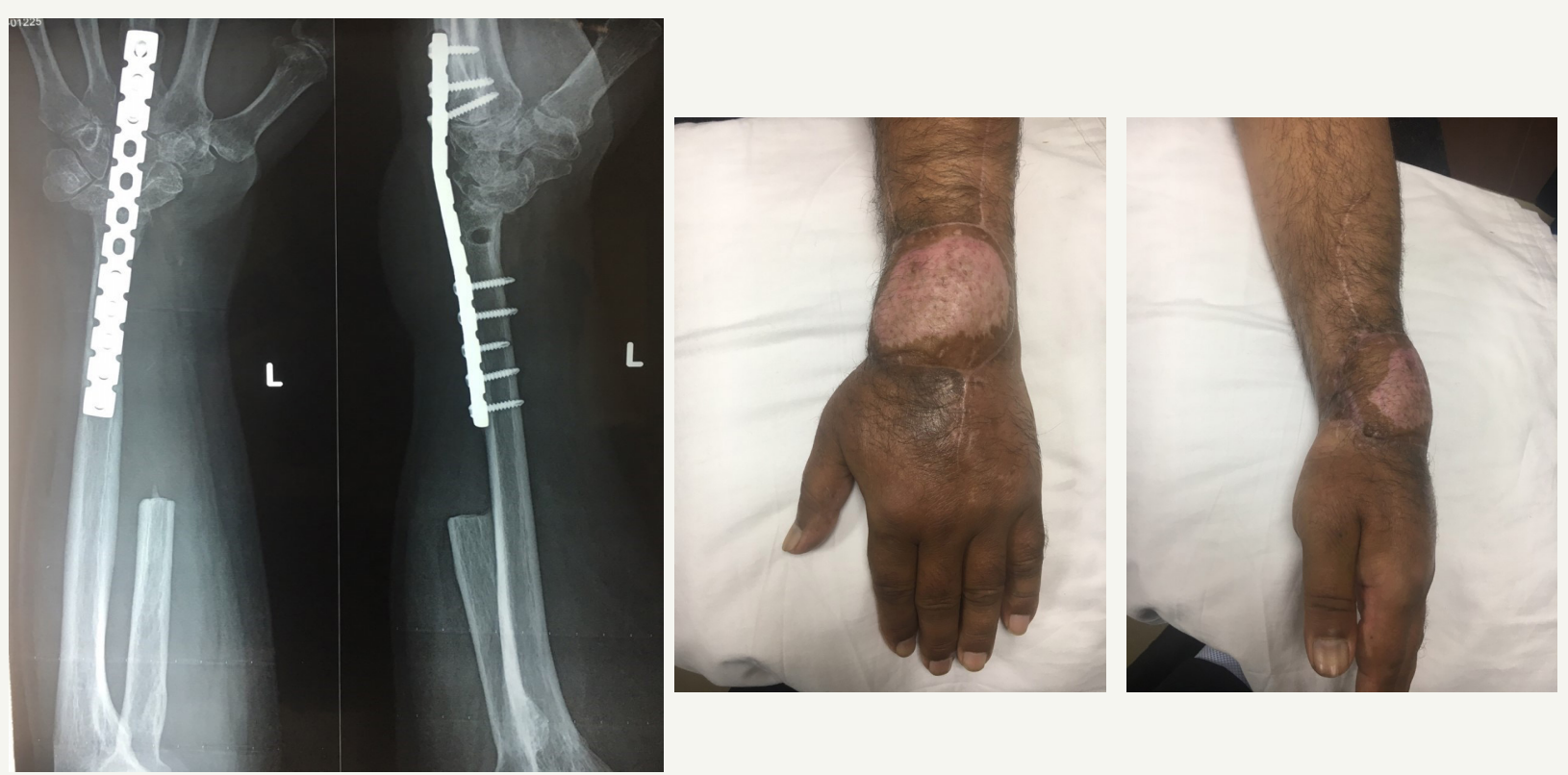

Figure 2: Patient in Figure 1 after neoadjuvant treatment with Denosumab for recurrence of GCT and resection of tumour followed by reconstruction with ulna centralisation. Patient also required a free abdominal flap. 
With the use of proximal fibula, although the advantage that is offered is its similarity in shape to the distal end of the radius but various complications including laxity due to the deficient lateral collateral ligament, knee pain, injury to common peroneal nerve and its associated sequelae have been described in the literature [11]. An arthrodesis provides a stable construct but at the expense of the movements at the wrist joint. On the contrary, an arthroplasty at the fibulocarpal site has had issues with instability. A quicker union is claimed when vascularised grafts are used but one study found no difference in between the two, however, acute bone grafting was used at the osteotomy site in the non-vascularised group [12].

An alternative technique to fibula autograft is ulna translocation or centralisation and ulnocarpal arthrodesis [13]. This reduces the morbidities associated with donor site and also has the benefit of being vascular which should potentially reduce the incidence of non-union. Furthermore, this is a relatively quicker and easier reconstruction technique which does not require microvascular skills. The advantage of ulna translocation over centralisation is the preservation of rotation noted with the aforementioned technique [14] (Figure $2 \& 3$ ). However, the opponents of ulna translocation or centralisation mention a thinner forearm which can be cosmetically unacceptable sometimes to the patients along with the risk of fracture as this being a single bone forearm. A thinner forearm may however facilitate closure of skin in cases of large fungating tumours or where a large proportion of soft tissue is lost. Other techniques that have been described in the literature for reconstruction are the use of tibial cortical strut and iliac crest with almost similar results as fibula autograft $[15,16]$ (Figure 4).
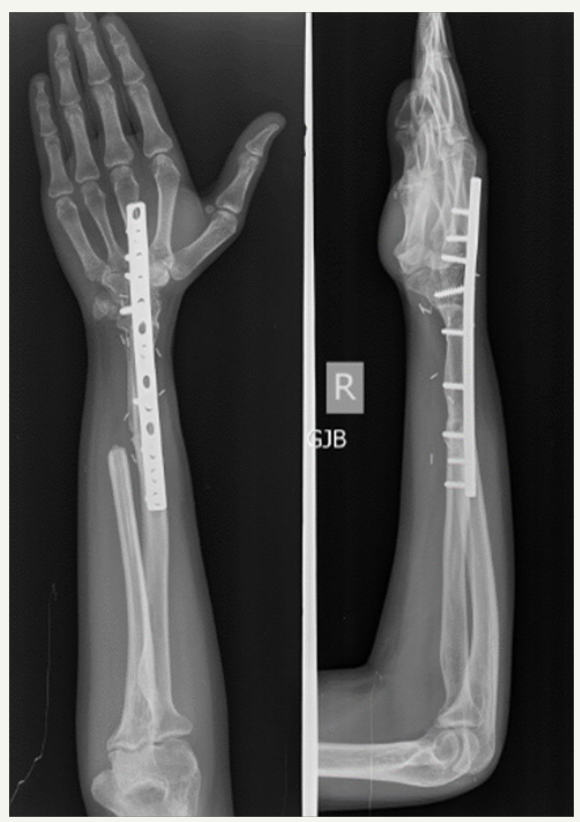

Figure 3: Two years post op x ray of Ulna translocation for a giant cell tumour showing solid union at osteotomy site.

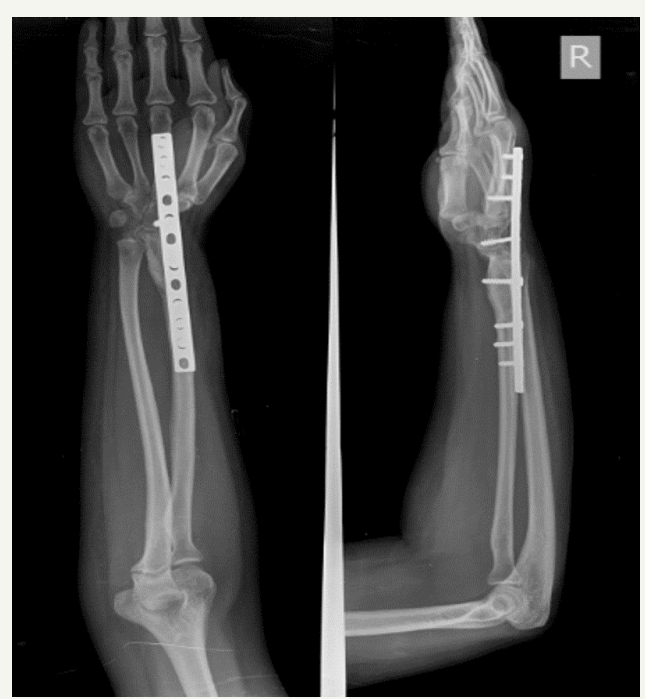

Figure 4: Resection of distal radius and reconstruction with iliac crest autograft. Follow up radiograph at 18 months from surgery. 
Allografts: Osteoarticular allografts offer the advantage of a good fit and no donor site co morbidity. However, concerns exist regarding union, resorption, fracture, disease transmission and joint wear over a period of time. Perhaps the most important limiting factor in the use of this technique is the availability of allograft $[17,18]$.

\section{Non biological reconstruction}

\section{A. Endoprosthesis}

Endoprosthesis: Endoprosthetic reconstruction after resection of tumours is a well-established and successful technique [19]. This however has not translated into its wide use in the distal radius and only some case reports are available in the literature of the use of endoprosthesis in this region. This technique was first described in the literature in 1957 and is exciting and attractive as it does not carry with it the burden of donor site morbidity but at the same time the lack of soft tissue cover and bulk of the prosthesis would be a concern regarding wound infection [20-22]. These endoprothesis are custom made and this can also be a reason for limiting its wider use due to availability of the technology.

\section{Arthrodesis Vs Arthroplasty}

Whatever form of reconstruction is used, the distal end of the construct is either used as an arthroplasty or arthrodesis. The proponents of arthroplasty claim better satisfaction with range of motion and on the contrary an arthrodesis provides a stable construct with no concerns of subluxation and instability [23]. A compromise in a functionally demanding patient between arthrodesis and arthroplasty maybe a partial fusion of the fibula autograft with scaphoid and lunate leaving some free movements at the midcarpal joint $[2,24]$.

\section{Conclusion}

In summary, the distal end of radius tumours offers a reconstructive challenge due to varying reasons as discussed. Biological reconstruction along with arthrodesis of the wrist is the mostly described technique in literature and offers a stable construct. However, an increase in expectations and functional demands from patients has led to various other techniques being tested with promising results. A review of the literature suggests that each of these techniques have some limitations and we would therefore suggest that these pathologies be dealt with by specialists with experience in dealing with bone tumours and utilise techniques of reconstruction with which they are most familiar and also depending on the availability of graft and implants.

\section{References}

1. Innocenti M, Delcroix L, Manfrini M, Ceruso M, Capanna R (2004) Vascularised proximal fibular epiphyseal transfer for distal radial reconstruction. J Bone Joint Surg Am 86-A(7): 1504-1511.

2. Minami A, Kato H, Iwasaki N (2002) Vascularized fibular graft after excision of giant-cell tumor of the distal radius: Wrist arthroplasty versus partial wrist arthrodesis. Plast Reconstr Surg 110(1): 112-117.
3. Ihara K, Doi K, Sakai K, Yamamoto M, Kanchiku T, et al. (1999) Vascularised fibular graft after excision of giant cell tumor of distal radius: A case report. Clin Orthop 359: 189-196.

4. Kumta SM, Leung PC, Yip K, Hung LK, Panozzo A, et al. (1998) Vascularised bone grafts in treatment of juxtra-articular giant cell tumors of bone. J Reconstr Microsurg 14: 185-190.

5. Taylor GI, Miller GD, Ham FJ (1975) The free bone graft: A clinical extension of microvascular techniques. Plast Reconstr Surg 55(5): 533544.

6. McKee DM (1978) Microvascular bone transplantation. Clin Plast Surg 5(2): 283-292.

7. Ostrup LT, Fredrikson JM (1974) Distant transfer of free lying bone graft by microvascular anastomosis. Plast Reconstr Surg 54(3): 274-285.

8. Weiland AJ, Philips JW, Randolf MA (1984) Bone graft: A radiological histological and biochemical model comprising autografts allograft and free vascularised bone grafts. Plast Reconstr Surg 74(3): 368-379.

9. Rtaimate M, Laffargue P, Farez E, Lariviere J, Branezelli MC (2001) Reconstruction of distal radius for primary bone tumors using a non vascularised fibular graft (report of 4 cases). Chir Main 20(4): 272-279.

10. Werner M (2006) Giant cell tumour of bone: morphological, biological and histogenetical aspects. Int Orthop 30(6): 484-489.

11. Murray JA, Schlafly B (1986) Giant-cell tumors in the distal end of the radius: treatment by resection and fibular autograft interpositional arthrodesis. J Bone Joint Surg 68(5): 687-694.

12. Saini R, Bali K, Bachhal V, Mootha AK, Dhillon MS, et al. (2011) En bloc excision and autogenous fibular reconstruction for aggressive giant cell tumor of distal radius: a report of 12 cases and review of literature. J Orthop Surg Res 6: 14.

13. Puri A, Gulia A, Agarwal MG, Reddy K (2010) Ulnar translocation after excision of a campanacci grade- 3 giant-cell tumour of the distal radius: an effective method of reconstruction. J Bone Joint Surg Br 92(6): 875879.

14. Bhagat S, Bansal M, Jandhyala R (2008) Wide excision and ulno-carpal arthrodesis for primary aggressive and recurrent giant cell tumours. Int Orthop 32(6): 741-745.

15. Leung PC, Chan KT (1986) Giant cell tumor of the distal end of the radius treated by the resection and free vascularized iliac crest graft. Clinical Orthop Relat Res 202: 232-236.

16. Van de Sande MA, van Geldorp NH, Dijkstra PD, Taminiau AH (2013) Surgical technique: Tibia cortical strut autograft interposition arthrodesis after distal radius resection. Clin Orthop Relat Res 471(3): 803-813.

17. Kocher MS, Gebhardt MC, Mankin HJ (1998) Reconstruction of the distal aspect of the radius with use of an osteoarticular allograft after excision of a skeletal tumor. J Bone Joint Surg Am 80(3): 407-419.

18. Scoccianti G, Campanacci DA, Beltrami G, Caldora P, Capanna R (2010) The use of osteo-articular allografts for reconstruction after resection of the distal radius for tumour. J Bone Joint Surg Br 92(12): 1690-1694.

19. Jeys LM, Kulkarni A, Grimer RJ, Carter SR, Tillman RM, et al. (2008) Endoprosthetic reconstruction for the treatment of musculoskeletal tumors of the appendicular skeleton and pelvis. J Bone Joint Surg Am 90(6): 1265-1271.

20. Gold AM (1957) Use of a prosthesis for the distal portion of the radius following resection of a recurrent giant-cell tumour. J Bone Joint Surg Am39-A(6): 1374-1380.

21. Gold AM (1965) Use of a prosthesis for the distal portion of the radius following resection of a recurrent giant-cell tumour. J Bone Joint Surg Am 47: 216-218. 
22. Hatano H, Morita T, Kobayashi H, Otsuka H (2006) A ceramic prosthesis for the treatment of tumours of the distal radius. Journal of Bone and Joint Surgery British 88(12): 1656-1658.

23. Vander Griend RA, Funderburk CH (1993) The treatment of giant-cell tumors of the distal part of the radius. J Bone Joint Surg Am 75(6): 899908.
24. Bickert B, Heitmann CH, Germann G (2002) Fibulo-scapho-lunate arthrodesis as a motion-preserving procedure after tumour resection of the distal radius. J Hand Surg Br 27(6): 573-576.
(C) (9) Creative Commons Attribution 4.0

For possible submissions Click Here

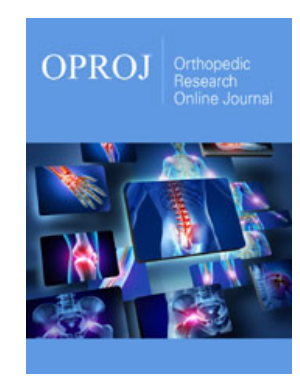

Orthopedic Research Online Journal

\section{Benefits of Publishing with us}

- High-level peer review and editorial services

- Freely accessible online immediately upon publication

- Authors retain the copyright to their work

- Licensing it under a Creative Commons license

- Visibility through different online platforms 